\title{
Malformación linfática quística del páncreas en un niño de 13 meses
}

\author{
Cystic lymphatic malformation of the pancreas in a 13-month-old child
}

\author{
Dra. María G. Salvo ${ }^{a}$ Dr. Brian M. Cavagnari ${ }^{a}$ Dr. José H. Méndez y Dr. Fernando L. Heinen ${ }^{b}$
}

\section{RESUMEN}

Las malformaciones linfáticas-previamente denominadas “linfangiomas"-son anomalías en el desarrollonormal del sistema linfático, con interrupción de su flujo y formación de cavidades quísticas con linfa. El 95\% se localiza en cuello y axila, siendo extremadamente rara la localización pancreática en niños. Las malformaciones linfáticas pancreáticas deben diferenciarse de otras masas quísticas del páncreas. Las localizadas en la cabeza del páncreas requieren, para su exéresis, una duodenopancreatectomía. Comunicamos el caso de un paciente de 13 meses de edad con una malformación linfática quística en la cabeza del páncreas, a quien se le realizó una duodenopancreatectomía. Un drenaje incesante de linfa del lecho tumoral llevó al deterioro inmunitario y a una sepsis incontrolable. Se plantean alternativas terapéuticas no quirúrgicas y se realiza una revisión de la bibliografía.

Palabras clave: malformación linfática, higroma quístico, duodenopancreatectomía, páncreas.

\section{SUMMARY}

Lymphatic malformations - previously called "lymphangiomas"-emerge due to an abnormal development of thelymphatic channels, with obstruction of the lymph flow and formation of lymphatic cysts. These cystic masses are frequently located in the neck and axillary region (95\%). A pancreatic localization is extremely rare in children. Pancreatic lymphatic malformations should be distinguished from other cystic pancreatic masses. For those located in the head of the pancreas, a pancreaticoduodenectomy is proposed. We report the case of a 13-monthold child with a lymphatic malformation on the pancreas head, resected through a pancreaticoduodenectomy. A persistent chylous drainage followed, causing immunitary impairment and an overwhelming sepsis. A non surgical approach to this lesion is discussed, and a literature review is made.

Key words: lymphatic malformation, cystic lymphangioma, pancreaticoduodenectomy, pancreas.

http:/ /dx.doi.org/10.5546/aap.2012.e25

\section{INTRODUCCIÓN}

Las malformaciones linfáticas (ML) -conocidas como "linfangiomas"- son entidades poco frecuentes. En los niños, las ML macroquísticas se localizan preferentemente en cuello $(75 \%)$ y axila (20\%). La localización pancreática se observa en menos del $1 \%$ de los casos y es más frecuente en mujeres adultas jóvenes. ${ }^{1,2}$

Al ser una patología de incidencia extremadamente baja en la edad pediátrica, el objetivo del presente artículo es presentar la evolución de un niño de 13 meses con una ML de cabeza de páncreas a quien se le realizó una duodenopancreatectomía cefálica (DPC), para luego discutir las distintas modalidades diagnósticas y terapéuticas con las que se cuenta al día de hoy para encarar esta patología.

\section{CASO CLÍNICO}

Un niño de 13 meses, sin antecedentes, consultó por llanto intermitente, leve dolor y distensión abdominal. Una radiografía simple de abdomen mostró una imagen opaca a nivel epigástrico (Figura 1) y la ecografía, una imagen quística centro-abdominal de $65 \times 65 \times 77 \mathrm{~mm}$ (Figura 2). Una tomografía computada con doble contraste (Figura 3), evidenció una masa quística que desplazaba el estómago y la primera porción duodenal hacia adelante. Se interpretó como un tumor quístico en la cabeza del páncreas, se plantearon varios diagnósticos diferenciales (Tabla 1) y se decidió su exploración quirúrgica. a. Departamento de Pediatría.

b. Servicio de Cirugía Pediátrica.

Hospital Alemán. Ciudad Autónoma de Buenos Aires.

Correspondencia:

Dr. Fernando L. Heinen: fheinen@hospitalaleman.com

Conflicto de intereses: Ninguno que declarar.

Recibido: 2-9-2011

Aceptado: 16-11-2011
Tabla 1. Principales causas de lesión quística de cabeza de páncreas $^{3}$

- Malformación linfática (linfangioma)

- Duplicación duodenal quística

- Neoplasias quísticas del páncreas (cistoadenomas, adenocarcinomas)

- Neoplasia sólido-quística (tumor de Frantz)

- Pancreatoblastoma quístico

- Hamartoma quístico 
El tumor, de $10 \times 10 \mathrm{~cm}$, comprimía al duodeno y la vía biliar extrahepática e incluía a la vena porta y a los vasos mesentéricos superiores. Para la resección completa fue necesaria una DPC con preservación del píloro, seguida de hepático-enteroanastomosis, anastomosis del páncreas distal al yeyuno y del duodeno-proximal al yeyuno, según

FIgURA 1. Rx simple de abdomen (de pie). La flecha señala una opacidad en epigastrio. Se aprecia el desplazamiento del estómago y de las asas intestinales.

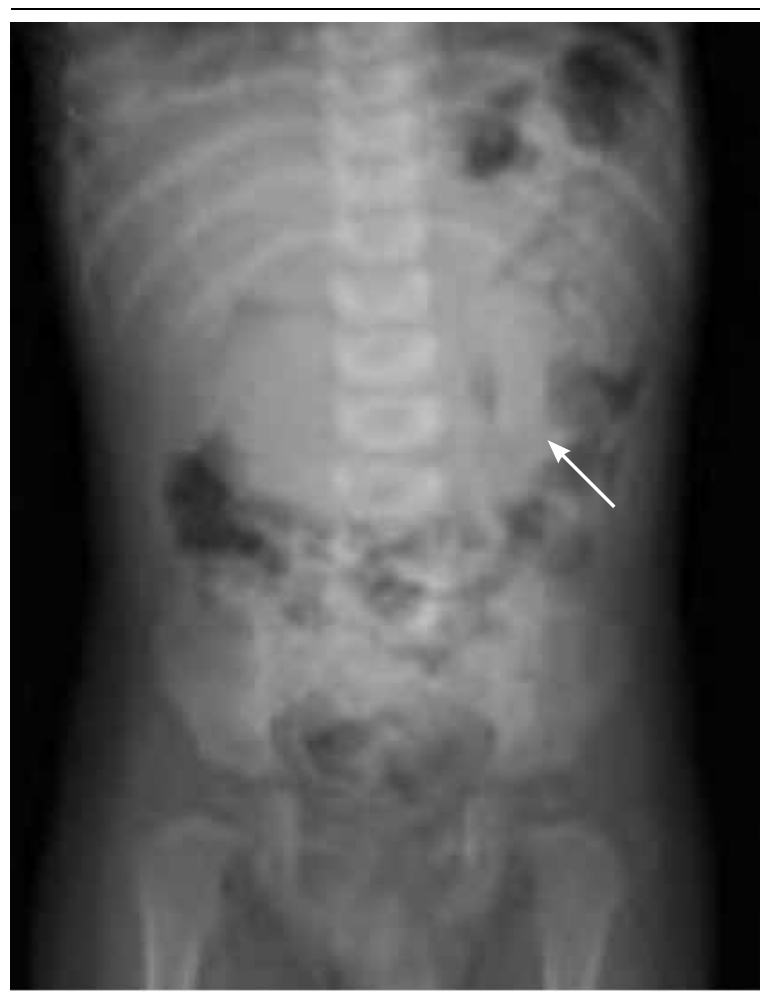

FIGURA 2. Ecografía abdominal. Se observa una imagen quística de $65 \times 65 \times 77 \mathrm{~mm}$ en el epigastrio.

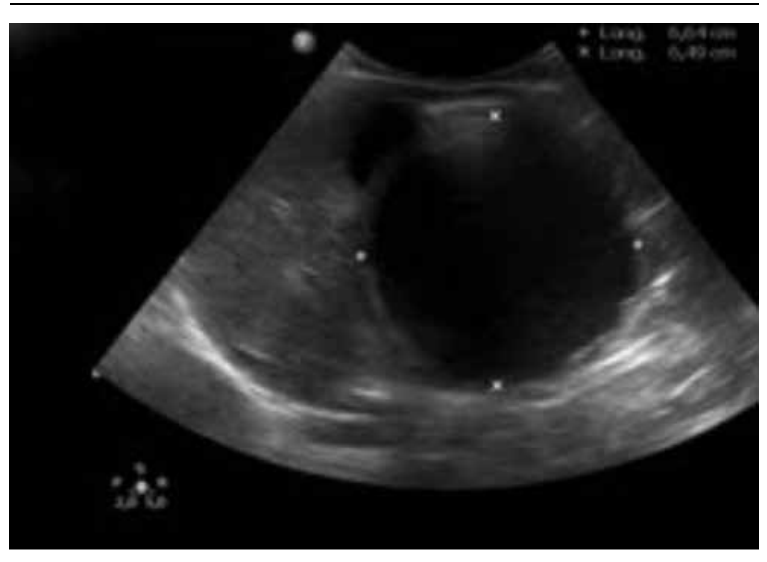

la reconstrucción post-DPC clásica a lo Child. La ML incluía la vena porta, por lo que se utilizó un injerto de vena cadavérica para mantener el flujo esplácnico luego de la resección. Se dejaron dos drenajes. La inmunomarcación histológica del tumor (CK negativo en la pared del quiste; CD34 y CD31 positivos en endotelio), correspondió a la de una ML.

El paciente presentó un drenaje constante de linfa (150-200 cc/kg/día) (Figura 4). El líquido opalescente contenía triglicéridos (313 mg/dl) y tenía predominio linfocitario. El volumen drenado se triplicaba ante los intentos de alimentación con aminoácidos esenciales y triglicéridos de cadena media por gastroclisis (Monogen ${ }^{\circledR}$, Nutricia), lo que obligó a la nutrición parenteral total (NPT). Durante 40 días postoperatorios, el volumen de la pérdida no varió a pesar de la utilización de octreótide endovenoso (Sandostatin ${ }^{\circledR}$, Novartis Pharma Corp.). La constante pérdida de linfa llevó al compromiso inmunitario del paciente, quien finalmente falleció -a los 57 días postoperatoriosproducto de un shock séptico con fallo multisistémico (aislamientos de Klebsiella oxitoca en la vía

FIgURA 3. Tomografía computada de abdomen (corte coronal). Tumor quístico pancreático (T); páncreas, cuerpo y cola de morfología normal (Pc); estómago desplazado (E); colédoco dilatado $(\mathrm{C})$.

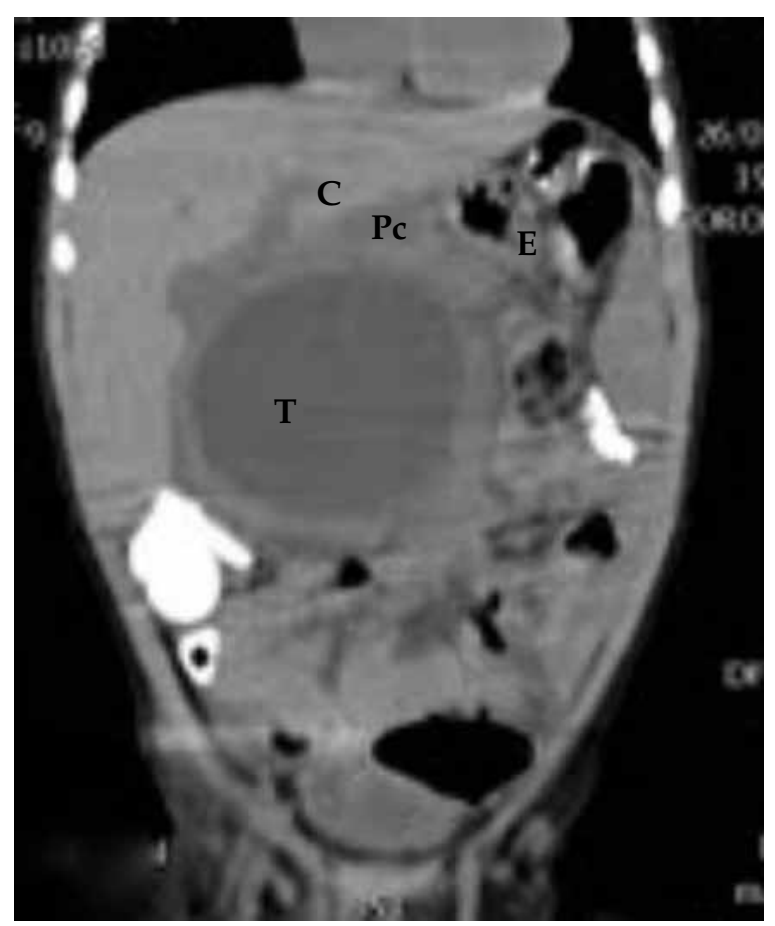


central, Proteus mirabilis en la orina y Staphylococcus aureus en el líquido drenado), a pesar del tratamiento con vancomicina, meropenem, amikacina $\mathrm{y}$ anfotericina.

\section{DISCUSIÓN}

Las ML son producto de una falla mesodérmica en el desarrollo y permeabilidad de los conductos linfáticos. ${ }^{4}$ La localización pancreática predomina en mujeres jóvenes y sólo se han comunicado casos aislados en niños. ${ }^{1,2}$ La presentación clínica es variable: desde una masa palpable, a un abdomen agudo por ruptura, hemorragia, obstrucción intestinal, torsión o compresión de estructuras vecinas. ${ }^{5,6}$ Los diagnósticos diferenciales incluyen al seudoquiste y las neoplasias quísticas pancreáticas $^{1,3,5}$ (Tabla 1). La histología de las ML muestra canales linfáticos dilatados con células endoteliales que presentan inmunorreactividad antifactor VIII-R y CD31. Los conductos están separados por septos con músculo liso y estroma con linfocitos. ${ }^{5}$ Las ML pancreáticas se localizan principalmente en el cuerpo y la cola, se incluyen en el parénquima pancreático y recidivan si la resección es parcial. ${ }^{7}$

FIgURA 4. Tomografía computada helicoidal de abdomen con contraste (corte transversal) en postoperatorio. Cambios postquirúrgicos por la duodeno-pancreatectomía cefálica, con alteración de los planos grasos a nivel del eje mesentérico. Líquido libre interasas en ambas fosas ilíacas y en fondo de saco de Douglas (ascitis quilosa). Se señala con flechas.

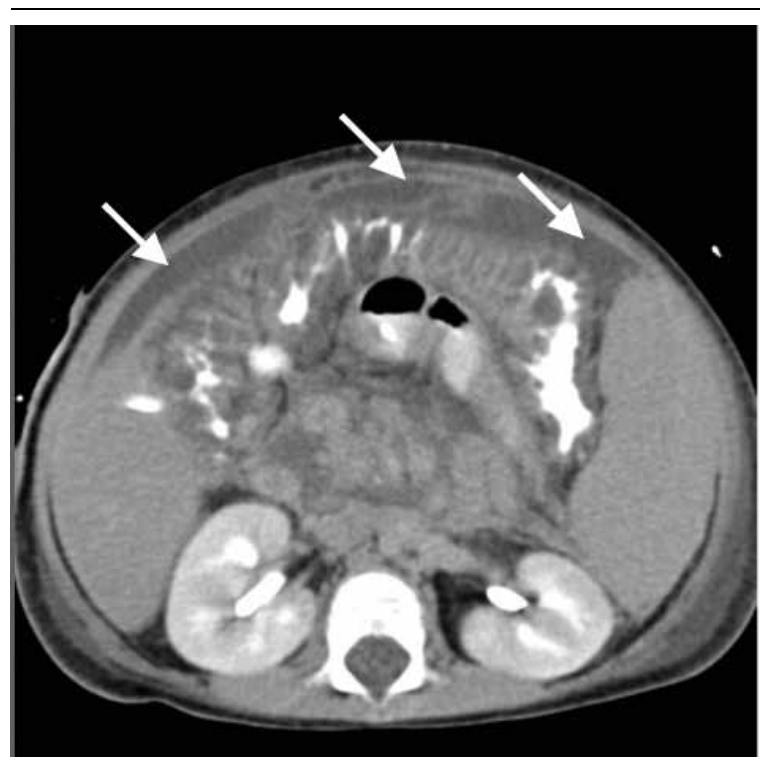

El tratamiento es la resección completa de la lesión ${ }^{8}$ o la esclerosis en casos pausiloculares o "higromas". ${ }^{9}$ En el cuerpo y cola del páncreas puede realizarse la exéresis del tumor con resección pancreática parcial o sin ella, $, 1,2,7$ pero cuando se localiza en la cabeza del páncreas, la resección completa obliga a una DPC. ${ }^{10}$

En nuestro caso, la inyección de esclerosantes en una masa pancreática compresiva, adyacente al duodeno y la vía biliar, fue considerada sólo luego del diagnóstico postoperatorio de la ML. Aunque hubiera sido una opción riesgosa por la topografía y el tamaño tumoral, quizás, el niño no hubiera tenido la evolución que referimos, luego de la DPC. Seguramente, ante un caso similar al presentado $-y$ considerando los resultados obtenidos con el tratamiento quirúrgico convencional- resultaría de mucha utilidad realizar previamente una angiorresonancia (para detectar el compromiso de la vena porta y de los vasos mesentéricos superiores) y una punciónaspiración del quiste para conocer la naturaleza de su contenido. Ambos métodos diagnósticos podrían orientar hacia conductas menos agresivas de tratamiento, como el mencionado uso de esclerosantes.

Es probable que, luego de la cirugía realizada, la apertura de miles de conductillos linfáticos anómalos que llenaban las grandes cavidades de la ML o la lesión de los conductos de drenaje linfático, haya producido la pérdida constante de linfa. ${ }^{11-13}$ No hubo complicación alguna inherente a la DPC en ninguna de sus tres anastomosis, pero el constante e incoercible drenaje linfático llevó al paciente a un déficit inmunitario que terminó en un shock séptico incontrolable. La linfa es rica en linfocitos, albúmina, fibrinógeno e inmunoglobulinas y su pérdida constante aumenta el riesgo de sepsis. 11,13

Para disminuir la pérdida linfática se cuenta con herramientas de uso progresivo: paracentesis evacuatorias, drenaje peritoneal y shunt peritoneo-venoso, dieta con triglicéridos de cadena media y NPT. ${ }^{13}$ El análogo de la somatostatina, octreótide, reduce el flujo sanguíneo esplácnico y la absorción de grasas. ${ }^{13}$ Algunos autores señalan que la NPT y el octreótide sumados, serían la primera línea de tratamiento. ${ }^{12}$ En casos todavía refractarios, podría resultar de utilidad la investigación laparoscópica o laparotómica del sitio de pérdida, mediante la administración enteral de Sudán Black B o azul de metileno, así como también intentar el sellado local con fibrina humana (Tissucol ${ }^{\circledR}$, Baxter Int. Inc.). 
Durante la espera requerida para la disminución del drenaje linfático, nuestro paciente sufrió una infección incontrolable. Así, cabe plantearse frente a un caso similar al presentado, la posibilidad de intentar inicialmente estrategias no quirúrgicas, como la inyección de algunos de los múltiples esclerosantes propuestos para el tratamiento de las ML. Algunas de estas sustancias -tal el caso de la bleomicina- han mostrado excelentes resultados. ${ }^{14}$ No obstante, no existen hasta el momento informes sobre el uso de esclerosantes en ML pancreáticas cefálicas y podrían no estar libres de complicaciones. ${ }^{15}$

\section{CONCLUSIÓN}

Las ML quísticas pancreáticas son infrecuentes y su presentación clínica es inespecífica. Las imágenes no pueden distinguir con certeza entre una ML y una neoplasia quística del páncreas. Hasta el momento, el tratamiento de elección para las ML de cuerpo y cola es quirúrgico. En las ML localizadas en la cabeza del páncreas -que requieren una DPC para su resección completa- existe el riesgo de complicaciones graves por ascitis quilosa. El uso de esclerosantes podría llegar a ser considerado en estos casos, aunque aún no hay suficiente experiencia publicada sobre su uso en ML de cabeza de páncreas.

\section{BIBLIOGRAFÍA}

1. Koenig TR, Loyer EM, Whitman GJ, Raymond AK, et al. Cysticlymphangioma of the pancreas. AJR Am J Roentgenol 2001;177(5):1090.

2. Colovic RB, Grubor NM, Micev MT, Atkinson HD, et al. Cystic lymphangioma of the pancreas. World J Gastroenterol 2008;14(44):6873-5.
3. Kosmahl M, Pauser U, Peters K, Sipos B, et al. Cystic neoplasms of the pancreas and tumor-like lesions with cystic features: a review of 418 cases and a classification proposal. Virchows Arch 2004;445(2):168-78.

4. Gray G, Fried K, Iraci J. Cystic lymphangioma of the pancreas: CT and pathologic findings. Abdom Imaging 1998;23(1):78-80.

5. Paal E, Thompson LD, Heffess CS. A Clinicopathologic and immunohistochemical study of ten pancreatic lymphangiomas and a review of the literature. Cancer 1998;82(11):2150-8

6. Daltrey IR, Johnson CD. Cystic lymphangioma of the pancreas. Postgrad Med J 1996;72(851):564-6.

7. Iglesias M, Yankovic F, Buchheister M, Arce JD, et al. Linfangioma quístico pancreático. Reporte de caso clínico y revisión de la literatura. Acta Med CSM 2010;4(1):37-40.

8. Casadei R, Minni F, SelvaS, Marrano N, etal. Cysticlymphangioma of the pancreas: anatomoclinical, diagnostic and therapeutic considerations regarding three personal observations and review of the literature. Hepatogastroenterology 2003;50(53):1681-6.

9. Huang Q, Ge B, Liu L, Tu Z, et al. Successful management of chylous ascites with total parenteral nutrition, somatostatin, and fibrin glue. Chin Med J (Engl) 2007;120(20):1847-9.

10. Igarashi A, Maruo Y, Ito T, Ohsawa K, et al. Huge cystic lymphangioma of the pancreas: report of a case. Surg Today 2001;31(8):743-6.

11. Olivar Roldán J, Fernández Martínez A, Martínez Sancho E, Díaz Gómez J, et al. Postsurgical chylous ascites: case report and literature review. Nutr Hosp 2009;24(6):748-50.

12. Madanur MA, Battula N, Azam MO, Heaton N, et al. Chylous ascites after pancreatico-duodenectomy cholangiocarcinoma xenografts in nude mice. Hepatobiliary Pancreat Dis Int 2007;6(4):416-9.

13. Huang Q, Jiang ZW, Jiang J, Li N, et al. Chylous ascites: Treated with total parenteral nutrition and somatostatin. World J Gastroenterol 2004;10(17):2588-91.

14. Cuervo JL, Galli E, Eisele G, Johannes E, et al. Malformaciones linfáticas: tratamiento percutáneo con bleomicina. Arch Argent Pediatr 2011;109(5):417-22.

15. Impellizzeri P, Romeo C, Borruto FA, Granata F, et al. Sclerotherapy for cervical cystic lymphatic malformations in children. Our experience with computed tomographyguided $98 \%$ sterile ethanol insertion and a review of the literatura. J Pediatr Surg 2010;45(12):2473-78. 